Boise State University

ScholarWorks

\title{
Linking in situ LAI and Fine Resolution Remote Sensing Data to \\ Map Reference LAI over Cropland and Grassland Using Geostatistical Regression Method
}

\author{
Yaqian He \\ Beijing Normal University \\ Yanchen Bo \\ Beijing Normal University \\ Leilei Chai \\ Beijing Normal University \\ Xiaolong Liu \\ Yunnan Normal University
}

Aihua Li

Boise State University

\section{Publication Information}

He, Yaqian; Bo, Yanchen; Chai, Leilei; Liu, Xiaolong; and Li, Aihua. (2016). "Linking in situ LAl and Fine Resolution Remote Sensing Data to Map Reference LAI over Cropland and Grassland Using Geostatistical Regression Method". International Journal of Applied Earth Observation and Geoinformation, 50, 26-38. https://doi.org/10.1016/j.jag.2016.02.010

\section{(c) (1)(9)}

This is an author-produced, peer-reviewed version of this article. @ 2016, Elsevier. Licensed under the Creative Commons Attribution-NonCommercial-NoDerivatives 4.0 License. Details regarding the use of this work can be found at: http://creativecommons.org/licenses/by-nc-nd/4.0/. The final, definitive version of this document can be found online at the International Journal of Applied Earth Observation and Geoinformation. doi: 10.1016/ j.jag.2016.02.010 
1 Linking in situ LAI and fine resolution remote sensing data to map reference LAI

2 over cropland and grassland using geostatistical regression method

3

4 Yaqian $\mathrm{He}^{\mathrm{a}, \mathrm{b}, \mathrm{c}}$, Yanchen $\mathrm{Bo}^{\mathrm{a}, \mathrm{b}, *}$, Leilei Chai ${ }^{\mathrm{a}, \mathrm{b}}$, Xiaolong Liu ${ }^{\mathrm{d}}$, Aihua $\mathrm{Li}^{\mathrm{e}}$

5

7

$8 \quad{ }^{\mathrm{b}}$ Beijing Key Laboratory for Remote Sensing of Environment and Digital Cities, Beijing

9 100875, China

$10{ }^{\mathrm{c}}$ Department of Geology and Geography, West Virginia University, Morgantown, WV

11 26506, USA

$12{ }^{\mathrm{d}}$ College of Tourism \& Geography Science, Yunnan Normal University, Kunming,

13 Yunnan Province 650500, China

$14{ }^{\mathrm{e}}$ Department of Geoscience, Boise State University, Boise, ID 83725, USA

15

$16 *$ Corresponding Author:

17 Dr. Yanchen Bo

18 State Key Laboratory of Remote Sensing Science, Research Center for Remote Sensing

19 and GIS, and School of Geography, Beijing Normal University, Beijing 100875, China

20 Tel.: +86-10-58802062

21 Fax: +86-10-58805274

22 E-Mail: boyc@bnu.edu.cn 
24 Abstract: Leaf Area Index (LAI) is an important parameter of vegetation structure. A

25 number of moderate resolution LAI products have been produced in urgent need of large

26 scale vegetation monitoring. High resolution LAI reference maps are necessary to

27 validate these LAI products. This study used a geostatistical regression (GR) method to

28 estimate LAI reference maps by linking in situ LAI and Landsat TM/ETM+ and SPOT-

29 HRV data over two cropland and two grassland sites. To explore the discrepancies of

30 employing different vegetation indices (VIs) on estimating LAI reference maps, this

31 study established the GR models for different VIs, including difference vegetation index

32 (DVI), normalized difference vegetation index (NDVI), and ratio vegetation index (RVI).

33 To further assess the performance of the GR model, the results from the GR and Reduced

34 Major Axis (RMA) models were compared. The results show that the performance of the

35 GR model varies between the cropland and grassland sites. At the cropland sites, the GR

36 model based on DVI provides the best estimation, while at the grassland sites, the GR

37 model based on DVI performs poorly. Compared to the RMA model, the GR model

38 improves the accuracy of reference LAI maps in terms of root mean square errors (RMSE)

39 and bias.

40

41 Keywords: Leaf Area Index; Up-scaling; Geostatistical Regression; Reduced Major Axis;

42 Vegetation Index 


\section{1. Introduction}

44 Leaf Area Index (LAI), defined as half the total leaf area per unit ground surface

45 areas (Chen and Black, 1992), is an important parameter of vegetation structure and

46 function (Abuelgasim et al., 2006). LAI provides substantial information on the exchange

47 of energy, mass, and momentum flux between the Earth's surface and its atmosphere

48 (Morisette et al., 2006; Myneni et al., 1997). LAI has been widely used as an input in

49 climate, hydrology, and biogeochemistry models (Berterretche et al., 2005; Knyazikhin et

50 al., 1998; Morisette et al., 2006). To date, a number of global and regional moderate-

51 resolution LAI products have been produced, including Moderate Resolution Imaging

52 Spectroradiometer (MODIS), Carbon Cycle and Change in Land Observational Products

53 from and Ensemble of Satellites (CYCLOPES), Canada Centre for Remote Sensing

54 (CCRS), and Global Land Surface Satellite (GLASS) (Chen et al., 2002; Tian et al.,

55 2000; Weiss et al., 2007; Xiao et al., 2014). Owing to the influence of model algorithms,

56 vegetation heterogeneity, and observation conditions, these LAI products inevitably have

57 inherent uncertainties (Chen et al., 2002), which subsequently may impact the accuracy

58 of any resulting modeling activities. Specifying the uncertainties of these coarse spatial

59 resolution LAI products is essential for users to determine the most appropriate dataset

60 for their applications, and for producers to improve methodological algorithms. However,

61 a direct comparison between in situ LAI measurements and these corresponding

62 moderate resolution LAI products is not recommended because of scale-mismatch,

63 geolocation errors, and land surface heterogeneity (Huang et al., 2006; Yang et al., 2006).

64 The proposed way to validate coarse resolution remote sensing products is using fine

65 reference maps derived from up-scaling in situ measurements (Fernandes et al., 2014; 
66 Iiames et al., 2015; Kang et al., 2015; Morisette et al., 2006; Wang et al., 2014). Previous

67 studies have generated fine resolution LAI reference maps through fusing in situ LAI

68 measurements and fine resolution remote sensing images (e.g. TM, ETM+, ASTER,

69 SPOT) (Baret et al., 2005; Chen et al., 2002; Cohen and Justice, 1999; Garrigues et al.,

70 2008; Li et al., 2013a; Martinez et al., 2009; Morisette et al., 2006; Pisek and Chen,

71 2007).

72 There are three categories of methods for estimating reference LAI maps using in

73 situ LAI observations and fine spatial resolution remote sensing data, including

74 regression, vegetation radiation transfer equation inversion, and geostatistical methods

75 (Cohen et al., 2003; Martinez et al., 2010; Yang et al., 2006). Of these, the radiation

76 transfer equation inversion method is not used widely due to the difficulty in collecting

77 certain model parameters (e.g. canopy structure) and the fact that the solution of the

78 model is not unique (Yang et al., 2006). Geostatistical methods have become popular in

79 linking field data to image data, and been applied to estimate forest parameters (basal

80 area, height, health conditions, etc), detect land use and land cover change, and map

81 vegetation index (e.g., normalized difference vegetation index: NDVI and LAI) (Van der

82 Meer, 2012). Traditional geostatistical methods, such as Kriging, predict unknown points

83 through spatially interpolating surrounding field observations (Berterretche et al., 2005;

84 Li et al., 2013a; Li et al., 2013b). The limited number of field observations and the spatial

85 non-stationarity of in situ observations distribution could lead to uncertainty of predicting

86 results. Regression methods, such as ordinary least squares regression, attempt to

87 improve the predicting accuracy through accounting for high resolution remote sensing

88 data (e.g., reflectance or vegetation indices (VI) derived from Landsat ETM+). Cohen et 
89 al. (2003) compared three regression methods (i.e., traditional ordinary least squares

90 regression, inverse ordinary least square regression, and reduced major axis: RMA) over

91 the BigFoot AGRO and NOBS sites. They reported that the performance of RMA method

92 was superior to the other two. However, none of the regression methods consider the

93 spatial/temporal correlation of in situ observations and high resolution reflectance or VI

94 data, which may lead to an underestimation of the uncertainty along with the regression

95 coefficients (Chatfield, 2003).

96 Geostatistical regression (GR) method conserves merits from both traditional

97 geostatistical methods and regression methods. It has been used in examining the

98 relationships between terrestrial carbon dioxide flux and its primary environmental

99 drivers (Mueller et al., 2010), and estimating snow cover and gross primary productivity

100 (Erickson et al., 2005; Yadav et al., 2010). Compared to traditional regression methods,

101 the GR method is improved in one distinct way, which is the ability to account for the

102 spatial/temporal correlation of the residuals from in situ observations (such as field LAI

103 measurements) and auxiliary data (such as NDVI) (Erickson et al., 2005; Mueller et al.,

104 2010; Yadav et al., 2010). Unlike traditional geostatistcal methods (e.g., Kriging), the GR

105 method attempts to provide better estimating of unknown points by exploring the

106 correlation between high resolution remote sensing data and field observations. To our

107 knowledge, no attempts have been made to use the GR method to estimate LAI reference

108 maps. This study applied the GR method to estimate high resolution LAI reference maps

109 over cropland and grassland sites through fusing in situ LAI measurements and high

110 resolution remote sensing images (i.e., Landsat TM/ETM+ and SPOT). To investigate the

111 discrepancy of employing different VIs on estimating LAI reference maps, this study 
112 established the GR models for the following VIs: difference vegetation index (DVI),

113 NDVI, and ratio vegetation index (RVI). To robustly assess the performance of the GR

114 model, the results from GR and RMA models were compared.

115

116 2. Methodology

117 2.1. Geostatistical regression method

118 The GR method not only models the relationships between auxiliary variables

119 (DVI, NDVI, and RVI in this study) and field measurements (in situ LAI measurements

120 in this study), but also accounts for the spatial/temporal correlation of the regression

121 residuals (Erickson et al., 2005). As with the linear regression method, the GR method

122 decomposes LAI into a deterministic and a stochastic component:

123

$$
L A I=X \beta+\varepsilon
$$

124 Where $X(n \times P)$ is the DVI, NDVI, and RVI, respectively, $\beta(P \times 1)$ is the

125 corresponding regression coefficient, and $\varepsilon(n \times 1)$ is assumed to be second-order

126 stationary and zero-mean residuals for DVI, NDVI, and RVI (Leung and Cooley, 2014;

127 Mueller et al., 2010; Yadav et al., 2010). Unlike the traditional linear regression

128 approach, which regards $\varepsilon$ as white noise, the GR method uses spatial covariance to

129 recognize the spatial autocorrelation structure of the regression residuals $\varepsilon$. The

130 experimental covariance of residuals $\varepsilon$ for DVI, NDVI and RVI, respectively, is:

$131 \quad Q(h)=E(\varepsilon(X) \varepsilon(X+h))$

132 Where $h$ is the spatial and/ or temporal distance, $Q(h)$ is the covariance of

133 residual at separation distance $h$ (Erickson et al., 2005). Many theoretical covariance

134 functions (such as nugget, exponential, spherical, and Gaussian functions) can be used to 
135 model the experimental covariance (Schabenberger and Pierce, 2001). In this study, a

136 linear combination of nugget and exponential functions is used following the previous

137 studies (Erickson et al., 2005; Li et al., 2013a; Mueller et al., 2010). This function is

138 defined as:

$$
Q(h)=\left\{\begin{array}{c}
\sigma_{N}^{2}+\sigma_{S}^{2}, h=0 \\
\sigma_{S}^{2} \exp \left(-\frac{h}{l}\right), h>0
\end{array}\right.
$$

$140 \quad \sigma_{N}^{2}$ is the measurement error or the variability at small scale that is uncorrelated in

141 space and/or time, $\sigma_{S}^{2}$ is the variance of the variability correlated in space and/or time,

142 and $l$ is the correlation range parameters (Leung and Cooley, 2014). The Restricted

143 Maximum Likelihood (RML), which maximizes the marginal distribution of the

144 covariance function parameters, is used to estimate the parameters $\left(\sigma_{N}, \sigma_{S}, l\right)$ (Kitanidis

145 and Shen, 1996).

146 The best linear unbiased estimator of $\beta$ on the basis of Aitken (1935) is the

147 generalized-least-squares estimator, that is, the value of $\beta$ that minimizes ( $L A I-$

$148 X \beta)^{T} Q^{-1}(L A I-X \beta)$. Thus,

$$
\hat{\beta}=\left(X^{T} Q^{-1} X\right)^{-1} X^{T} Q^{-1} L A I
$$

150

151

\subsection{Reduced major axis method}

152 To robustly assess the performance of the GR model, we compare the results from

153 GR and RMA models. We choose RMA method because it is regarded as the 'standard'

154 method for estimating LAI reference map in BigFoot project (Berterretche et al., 2005;

155 Cohen et al., 2003), which is a well known project linking in situ measurements, remote

156 sensing and models to validate MODIS products including LAI product. The form of

157 RMA is identical to a simple linear regression method: 


$$
L A I=\beta_{0}+\beta_{1} X+\varepsilon
$$

Where $X$ is DIV, NDVI, and RVI, respectively. $\varepsilon$ is white noise residual.

160 RMA method is superior to traditional ordinary least squares regression when

161 both dependent (LAI in this study) and independent variables (DVI, NDVI, and RVI in

162 this study) are measured with errors (Cohen et al., 2003; Smith, 2009). The estimating of

$163 \beta_{0}$ and $\beta_{1}$ is different with the traditional ordinary least square regression. The traditional

164 ordinary least square regression estimates the regression coefficients by minimizing the

165 sum of squares of the residuals, while RMA minimizes the areas of triangles formed by

166 the deviation of a point from the regression line in both horizontal and vertical directions

167 (Smith, 2009). The equations for calculating $\beta_{0}$ and $\beta_{1}$ are $\beta_{0}=\overline{L A I}-\frac{\sigma_{Y}}{\sigma_{X}} \bar{X}$ and $\beta_{1}=\frac{\sigma_{Y}}{\sigma_{X}}$.

169 3. Data

170 3.1. Study Sites

171 Two cropland sites (AGRO and Plan-de-dieu sites) and two grassland sites

172 (Hulun Buir and Zhangbei sites) were used in this study. The AGRO site is from the

173 BigFoot project (http://www.fsl.orst.edu/larse/bigfoot/index.html), which is funded by

174 NASA’S Terrestrial Ecology Program (Morisette et al., 2006; Pisek and Chen, 2007).

175 Nine validation sites are in the BigFoot project with each of them covering a $5 \mathrm{~km} \times 5 \mathrm{~km}$

176 extent (Morisette et al., 2006). The field LAI values in the AGRO site were measured by

177 the allometric destructive method. The Hulun Buir site is one of the validation sites for

178 the GLASS LAI product, which is a newly released LAI product generated by Beijing

179 Normal University, China (Liang et al., 2014). The coverage of the Hulun Buir site is

180 about $32 \mathrm{~km} \times 28 \mathrm{~km}$. The in situ LAI values in the Hulun Buir were measured by LAI- 
181 2000. The Plan-de-dieu and Zhangbei sites are from the VALERI project

182 (http://w3.avignon.inra.fr/valeri/), which has served to provide high spatial resolution

183 maps of biophysical variables (e.g., LAI, fAPAR, fCover) to validate products derived

184 from satellite observations (e.g., VEGETATION, MERIS, POLDER, AVHRR, and

185 MODIS) (Baret et al., 2005). The VALERI project has 33 sites, each of them covering

186 around $3 \mathrm{~km} \times 3 \mathrm{~km}$. The in situ LAI values in the VALERI project were measured by

187 LAI-2000 or hemispherical images.

188 The AGRO site is located in Bondville, Illinois, USA. The main crop types of the

189 AGRO site are corn and soybean (Pisek and Chen, 2007). The Plan-de-dieu site, with its

190 main crop being vineyards, is located at Cotes du Rhone Village, France (Rossello,

191 2007). The Hulun Buir and Zhangbei grassland sites are located in Inner Mongolia and

192 Hebei, China, respectively. The Landsat TM/ETM+ for AGRO and Hulun Buir sites were

193 employed in this study as high resolution remote sensing images, because they are

194 commonly used in up-scaling field measurements (Berterretche et al., 2005; Cohen et al.,

195 2003) and could be easily obtained. We chose SPOT-HRV for Plan-de-dieu and

196 Zhangbei sites because the Landsat TM/ETM+ corresponded to the date of in situ LAI in

197 these two sites has gaps and does not have good quality, while SPOT-HRV images have

198 been collected for many sites in VALERI project including Plan-de-dieu and Zhangbei

199 sites (Baret et al., 2005). The in situ LAI, TM/ETM+, and HRV data on the exact same

200 date were not available. Therefore the data on the closest dates were chosen. The detailed

201 information of the four sites is described in Table 1 . The locations of the four study sites

202 and the corresponding distribution of the in situ LAI locations in each site are shown in

203 Figure 1. 
Table 1. Information of the four study sites.

\begin{tabular}{|c|c|c|c|c|c|c|c|c|}
\hline Sites & $\begin{array}{c}\text { UTM } \\
\text { X } \\
\text { Coord }\end{array}$ & $\begin{array}{l}\text { UTM Y } \\
\text { Coord }\end{array}$ & $\begin{array}{l}\text { UTM } \\
\text { Zone }\end{array}$ & Location & $\begin{array}{l}\text { Vegetation } \\
\text { types }\end{array}$ & $\begin{array}{c}\text { Datasets } \\
\text { used }\end{array}$ & $\begin{array}{c}\text { Datasets when } \\
\text { obtained }\end{array}$ & $\begin{array}{c}\text { In situ LAI } \\
\text { measurement } \\
\text { method }\end{array}$ \\
\hline AGRO & 389764 & 4429295 & $16 \mathrm{~N}$ & $\begin{array}{l}\text { Illinois } \\
\text { USA }\end{array}$ & $\begin{array}{l}\text { Corn and } \\
\text { Soybean }\end{array}$ & $\begin{array}{l}\text { Field } \\
\text { LAI; } \\
\text { ETM+; } \\
\text { Land } \\
\text { cover }\end{array}$ & $\begin{array}{c}7 / 24 / 2000 \\
7 / 15 / 2000 \\
2000\end{array}$ & $\begin{array}{l}\text { Allometric } \\
\text { destructive } \\
\text { means }\end{array}$ \\
\hline $\begin{array}{l}\text { Plan-de- } \\
\text { dieu }\end{array}$ & 655669 & 4895787 & $31 N$ & $\begin{array}{l}\text { Cotes du } \\
\text { Rhone } \\
\text { Village } \\
\text { France }\end{array}$ & Vineyards & $\begin{array}{l}\text { Field } \\
\text { LAI; } \\
\text { SPOT; }\end{array}$ & $\begin{array}{c}\text { 7/05-7/09/2004 } \\
6 / 29 / 2004\end{array}$ & $\begin{array}{c}\text { Hemispherical } \\
\text { images }\end{array}$ \\
\hline Hulun Buir & 717675 & 5473425 & $50 \mathrm{~N}$ & $\begin{array}{l}\text { Inner } \\
\text { Mongolia } \\
\text { China }\end{array}$ & Grassland & $\begin{array}{l}\text { Field } \\
\text { LAI; } \\
\text { TM; } \\
\text { Land } \\
\text { cover }\end{array}$ & $\begin{array}{l}6 / 26 / 2010 \\
6 / 21 / 2010 \\
2010\end{array}$ & LAI-2000 \\
\hline Zhangbei & 306354 & 4572278 & $50 \mathrm{~N}$ & $\begin{array}{l}\text { Hebei } \\
\text { China }\end{array}$ & Grassland & $\begin{array}{l}\text { Field } \\
\text { LAI; } \\
\text { SPOT; }\end{array}$ & $\begin{array}{c}\text { 8/08/-8/10/2002 } \\
8 / 23 / 2002\end{array}$ & $\begin{array}{l}\text { Hemispherical } \\
\text { images }\end{array}$ \\
\hline
\end{tabular}



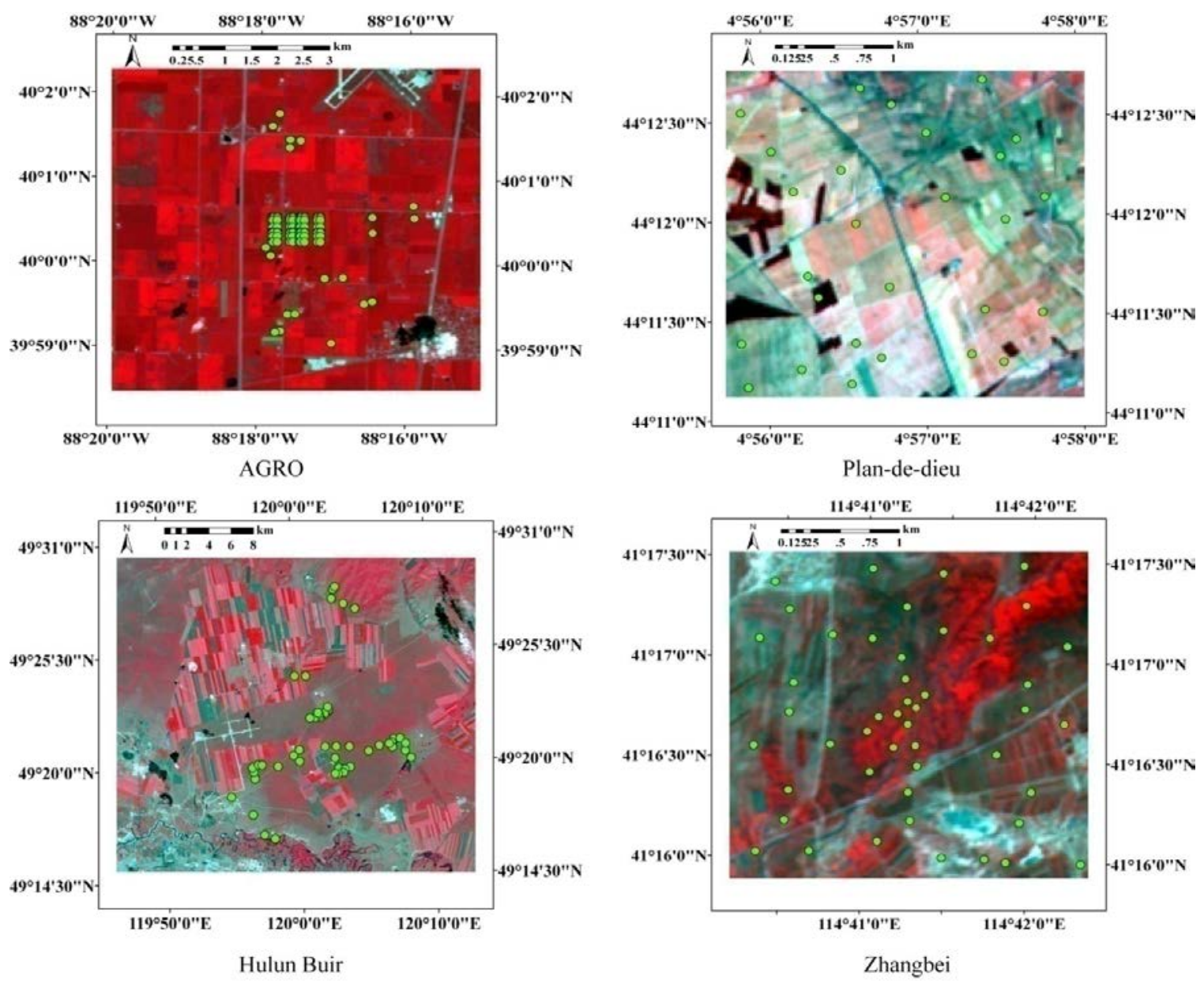

206 Figure 1. Study sites of the AGRO, Plan-de-dieu, Hulun Buir, and Zhangbei (the

207 background is the standard false color composited image, and the green points are the in

208 situ LAI locations).

209

210

\subsection{Data pre-processing}

211 Landsat TM/ETM+ data with $30 \mathrm{~m}$ spatial resolution used in this study were

212 downloaded from the USGS website (http://glovis.usgs.gov/). The TM/ETM+ data are

213 Level 1T data that have been systematically, radiometrically, and geometrically

214 corrected. A large proportion of images are contaminated due to the influence of aerosols,

215 clouds, and cloud shadows (Liang et al., 2001). The TM/ETM+ data were

216 atmospherically corrected by the Landsat Ecosystem Disturbance Adaptive Processing

217 System (LEDAPS) (Masek et al., 2006). The two study areas, the AGRO and Hulun Buir 
218 sites, were extracted using ENVI software (Figure 1). The SPORT-HRV data with a

219 spatial resolution of $20 \mathrm{~m}$ over the Plan-de-dieu and Zhangbei sites were obtained from

220 the VALERI project (see the link in 3.1). Though they were geometrically corrected, no

221 atmospheric corrections were applied to the images since no atmospheric data were

222 available (Rossello, 2007, 2008). Rossello (2007) stated that atmospheric effects were

223 assumed to be the same over the whole $3 \mathrm{~km} \times 3 \mathrm{~km}$ extent, since the SPOT images were

224 used to compute empirical relationships between reflectance and biophysical variables.

225 The biophysical variables in the VALERI project over most of the 33 sites were based on

226 SPOT-HRV top of atmosphere (TOA) reflectance (Baret et al., 2005). Following

227 previous studies, this study also used the SPOT-HRV TOA reflectance to obtain the LAI

228 values over the Plan-de-dieu and Zhangbei sites.

229 To evaluate the impacts of different vegetation indices on the GR and RMA

230 models, this study employed DVI, NDVI, and RVI. The forms of these vegetation indices

231 are: (Colombo et al., 2003; Huete et al., 2002).

232

$$
D V I=N I R-R
$$

$N D V I=(N I R-R) /(N I R+R)$

$R V I=N I R / R$

$235 \quad$ NIR is reflectance of near infrared band and $R$ is reflectance of red band.

236 The scatter plots of DVI, NDVI, and RVI with the in situ LAI measurements at

237 the four study sites are shown in Figure 2. At the AGRO site, DVI, NDVI, and RVI of the

238 corn and soybean crop types have apparent boundaries. This study thus established the

239 GR and RMA models for these two crop types, respectively. The land cover data from

240 the BigFoot project was used to distinguish the corn and soybean over the AGRO site 
241 (Table 1). As the Hulun Buir covered around $896 \mathrm{~km}^{2}$, which may include other types of

242 vegetation (e.g., forest), the land cover data used in this study to mask the non-grassland

243 regions was provided by Tsinghua University (Table 1), China (Gong et al., 2013; Yu et

244 al., 2013).
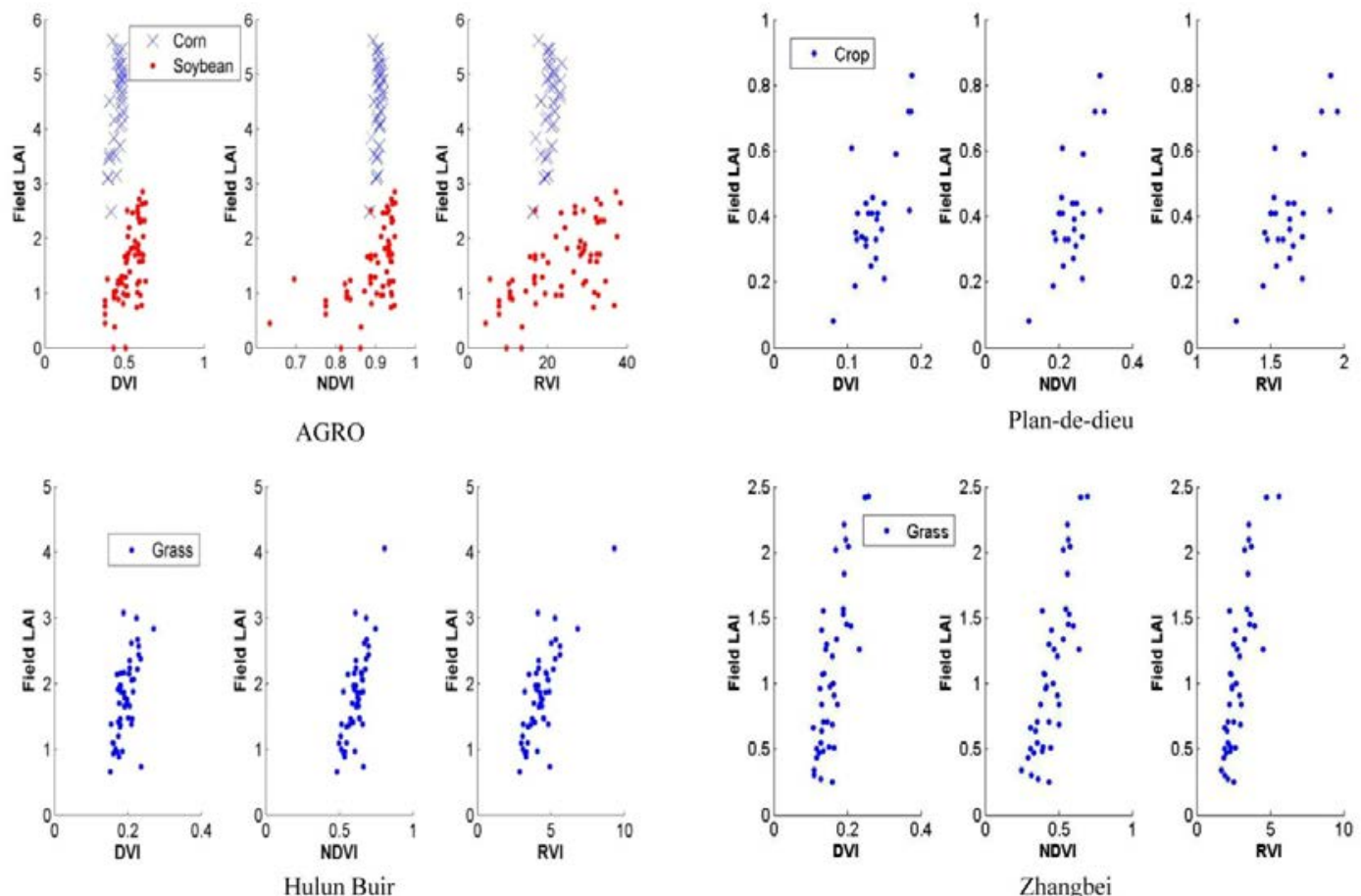

246 Figure 2. The scatter plots of DVI, NDVI, and RVI with the in situ LAI at the AGRO, Plan-de-dieu, Hulun Buir, and Zhangbei sites.

250 Zhangbei sites are 98, 26, 51, and 42, respectively. This study randomly selected around

$25165 \%$ of the LAI points to establish and specify the GR and RMA models. The 35\% of the

252 LAI points were used to validate the results. This was repeated another five times for the

253 GR models, in order to cross validate the robustness of performance of the models. 


\section{4. Results and Discussion}

258 4.1. Spatial covariance models

259 As stated in 2.1, the residuals for Equation (1) were assumed to be second-order

260 stationary with zero-mean, we calculated the experimental isotropic covariance of the

261 residuals using least square method (Li et al., 2013b). The experimental covariances were

262 modeled with exponential functions. The parameters of exponential functions were

263 obtained through RML method. Table 2 shows the parameters of exponential functions

264 for different VIs at four sites, respectively. The experimental and modeled covariances

265 are shown in Figure 3. The parameters of covariance function in the same site have very

266 similar values, which indicate similar spatial structure happens in the same site no matter

267 what the VI is. At different sites the parameters are quit different (Table 2), depending on

268 the locations of in situ LAI measurements and associations between LAI and VIs in that

269 site. In addition to nugget variance for DVI at AGRO (Corn) site, all of the nugget values

270 are larger than zero, which may be due to the heterogeneous of LAI of sub-samples

271 within each sample, since the in situ LAI value for each sample is calculated from sub-

272 samples in that sample (Baret et al., 2005; BigFoot, 1999). For example, each in situ LAI

273 sample plot in Zhangbei site covers around $20 \mathrm{~m}$ x $20 \mathrm{~m}$. In each sample plot, 12 sub-

274 samples are used to calculate the corresponding LAI value for that sample plot (Baret et 275 al., 2005).

Table 2. Parameters of the covariance function

\begin{tabular}{ccccc}
\hline Site & VIs & $\sigma_{N}$ & $\sigma_{s}$ & $l$ \\
\hline & DVI & 0.000 & 0.278 & 193.862 \\
\cline { 2 - 5 } AGRO & NDVI & 0.099 & 0.361 & 193.862 \\
\cline { 2 - 5 }$($ Corn $)$ & RVI & 0.104 & 0.356 & 193.862 \\
\hline
\end{tabular}




\begin{tabular}{ccccc}
\hline \multirow{2}{*}{$\begin{array}{c}\text { AGRO } \\
\text { (Soybean) }\end{array}$} & DVI & 0.069 & 0.184 & 142.228 \\
\cline { 2 - 5 } & NDVI & 0.067 & 0.184 & 142.228 \\
\cline { 2 - 5 } & RVI & 0.062 & 0.194 & 142.228 \\
\hline \multirow{2}{*}{ Plan-de-dieu } & DVI & 0.003 & 0.010 & 1505.988 \\
\cline { 2 - 5 } & NDVI & 0.003 & 0.011 & 1505.988 \\
\cline { 2 - 5 } & RVI & 0.003 & 0.011 & 1505.988 \\
\hline \multirow{2}{*}{ HulunBuir } & DVI & 0.053 & 0.212 & 2501.122 \\
\cline { 2 - 5 } & NDVI & 0.047 & 0.187 & 2501.122 \\
\cline { 2 - 5 } & RVI & 0.044 & 0.174 & 2501.122 \\
\hline \multirow{2}{*}{ Zhangbei } & DVI & 0.026 & 0.104 & 699.860 \\
\cline { 2 - 5 } & NDVI & 0.024 & 0.096 & 699.860 \\
\cline { 2 - 5 } & RVI & 0.022 & 0.088 & 699.860 \\
\hline
\end{tabular}

277

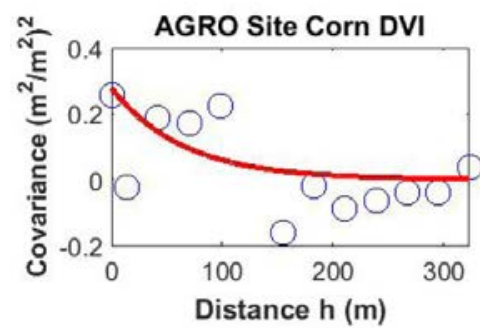

(1)

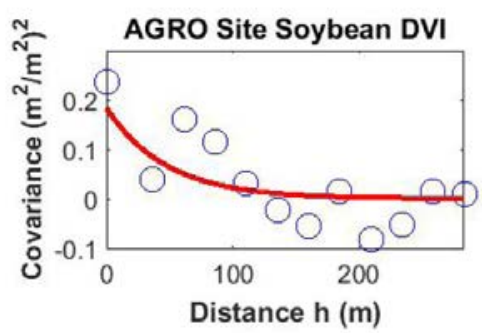

(4)

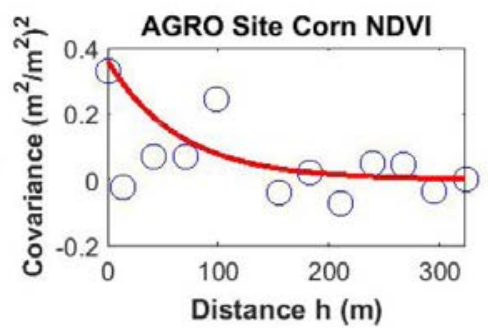

(2)

AGRO (Corn)

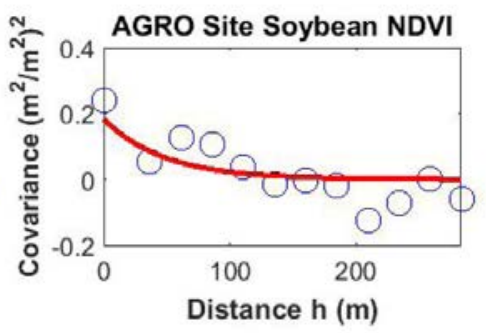

(5)

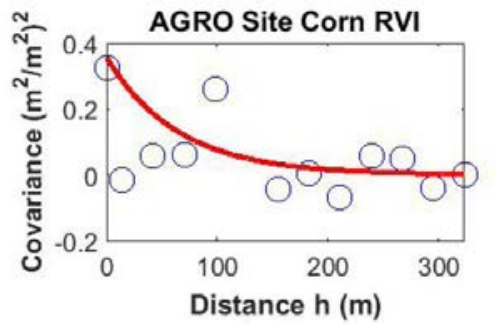

(3)

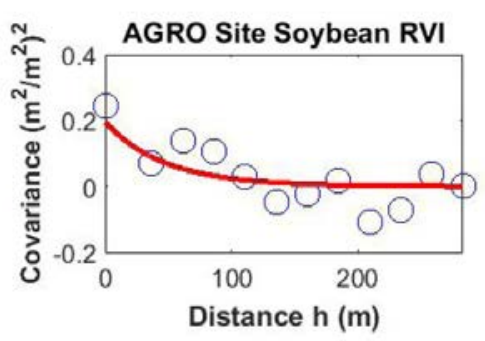

(6)

AGRO (Soybean) 


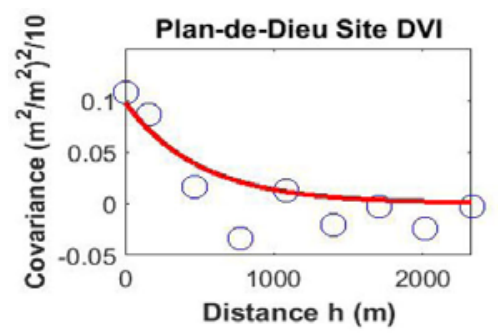

(7)

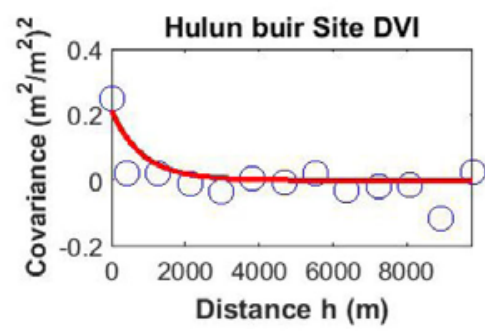

(10)

279

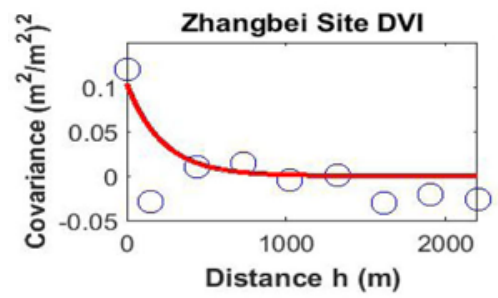

(13)

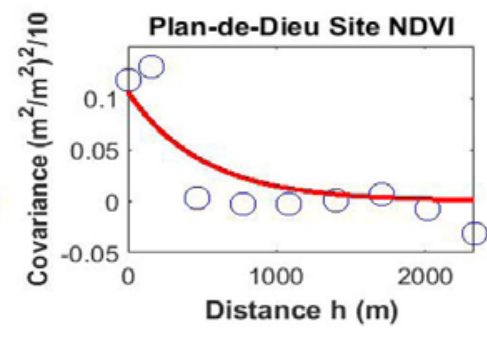

(8)

Plan-de-dieu

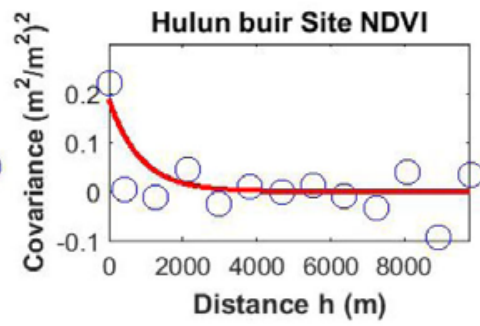

(11)

Hulun Buir

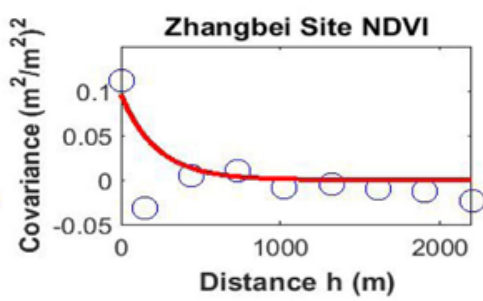

(14)

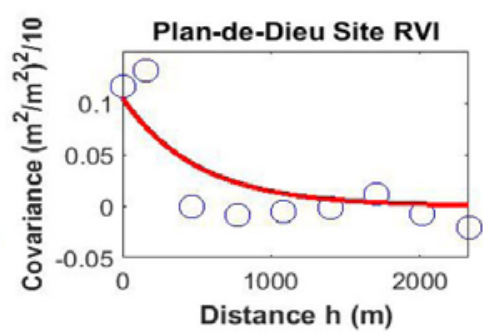

(9)

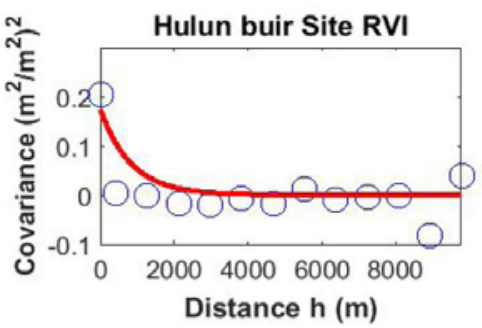

(12)

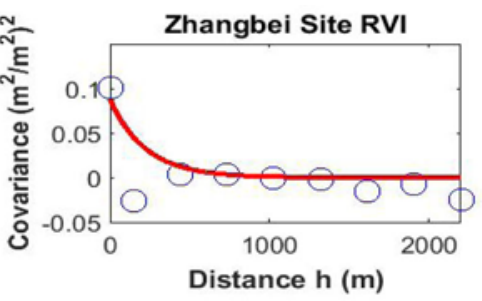

(15)

Zhangbei

281 Figure 3. The experimental and modeled covariance (blue circle is experimental covariance, and red line is modeled covariance)

\subsection{GR models for the four study sites}

Table 3 shows the GR models for the AGRO, Plan-de-dieu, Hulun Buir, and

286 Zhangbei sites. The values in parentheses are standard deviations for slope and intercept.

287 The significance of slope and intercept are tested by Student's t test. Besides slopes for

288 NDVI and RVI in the AGRO (corn) sites, all slopes are significant at 1\% level, indicating

289 the reliability of the models. The majority of intercepts are not significant at 1\% level,

290 excepting the intercepts in Zhangbei site. The insignificance may be due to small

291 samples, such as the AGRO (corn) and Plan-de-dieu sites. The negative values of 
292 intercept may be attributed to the uncertainty of retrieving DIV, NDVI, and RVI from

293 TM/ETM+ and HRV images, as there is no accurate atmosphere information for each

294 sites, thereby the band reflectance from these images has errors. In addition, the in situ

295 LAI values also have measurement errors. Therefore, the negative values of intercept are 296 shown when conducting statistical analysis.

297 The coefficient of determination $\left(\mathrm{R}^{2}\right)$ varies among different models in different 298 sites. At the AGRO site, the $\mathrm{R}^{2}$ value for corn ranges from 0.28 to 0.44 , and for soybean

2990.38 to 0.40 . The $\mathrm{R}^{2}$ value of DVI model is the highest for the AGRO site compared to 300 the $\mathrm{R}^{2}$ values for NDVI and RVI models. As with the AGRO site, the $\mathrm{R}^{2}$ value of DVI

301 model in the Plan-de-dieu site is the highest. The $\mathrm{R}^{2}$ value for the Hulun Buir and

302 Zhangbei grassland sites ranges from 0.53 to $0.61,0.63$ to 0.69 , respectively. In contrast

303 to the cropland sites (i.e., the AGRO and Plan-de-dieu sites), the $\mathrm{R}^{2}$ values of DVI models

304 over the two grassland sites are the lowest. Excepting for Zhangbei site, the $\mathrm{R}^{2}$ values are

305 not high, which maybe because of the poor relationships between DVI, NDVI, and RVI

306 and original in situ LAI values (Figure 2). However, the GR models with DVI perform

307 best over the two cropland sites, while for the two grassland sites, the GR models with 308 DVI have the poorest performance.

Table 3. GR models at the four study sites.

\begin{tabular}{ccccc}
\hline Site & VIs & $\mathbf{R}^{2}$ & Slope & Intercept \\
\hline \multirow{3}{*}{ AGRO } & DVI & 0.44 & $14.62 * *$ & -2.29 \\
$($ Corn) & & & $(4.02)$ & $(1.81)$ \\
\cline { 2 - 5 } & NDVI & 0.28 & 23.56 & -17.16 \\
& & & $(20.35)$ & $(18.40)$ \\
\cline { 2 - 5 } & RVI & 0.29 & 0.10 & 2.20 \\
& & & $(0.09)$ & $(1.76)$ \\
\hline
\end{tabular}




\begin{tabular}{|c|c|c|c|c|}
\hline \multirow[t]{3}{*}{$\begin{array}{c}\text { AGRO } \\
\text { (Soybean) }\end{array}$} & DVI & 0.4 & $\begin{array}{c}5.35^{* *} \\
(1.09)\end{array}$ & $\begin{array}{c}-1.23 * \\
(0.56)\end{array}$ \\
\hline & NDVI & 0.4 & $\begin{array}{c}8.55^{* *} \\
(1.71)\end{array}$ & $\begin{array}{c}-6.23^{* *} \\
(1.55)\end{array}$ \\
\hline & RVI & 0.38 & $\begin{array}{c}0.05^{* *} \\
(0.01)\end{array}$ & $\begin{array}{c}0.41 \\
(0.24)\end{array}$ \\
\hline \multirow[t]{3}{*}{ Plan-de-dieu } & DVI & 0.57 & $\begin{array}{c}4.47 * * \\
(1.01)\end{array}$ & $\begin{array}{l}-0.17 \\
(0.14)\end{array}$ \\
\hline & NDVI & 0.53 & $\begin{array}{c}2.53 * * \\
(0.61)\end{array}$ & $\begin{array}{l}-0.16 \\
(0.14)\end{array}$ \\
\hline & RVI & 0.54 & $\begin{array}{c}0.75^{* *} \\
(0.18)\end{array}$ & $\begin{array}{c}-0.78 * \\
(0.29) \\
\end{array}$ \\
\hline \multirow[t]{3}{*}{ HulunBuir } & DVI & 0.53 & $\begin{array}{c}15.46 * * \\
(2.62)\end{array}$ & $\begin{array}{l}-1.25^{*} \\
(0.52)\end{array}$ \\
\hline & NDVI & 0.58 & $\begin{array}{c}8.41 * * \\
(1.28)\end{array}$ & $\begin{array}{c}-3.39 * * \\
(0.79)\end{array}$ \\
\hline & RVI & 0.61 & $\begin{array}{c}0.50 * * \\
(0.07)\end{array}$ & $\begin{array}{l}-0.41 \\
(0.32)\end{array}$ \\
\hline \multirow[t]{3}{*}{ Zhangbei } & DVI & 0.63 & $\begin{array}{c}13.82 * * \\
(2.13)\end{array}$ & $\begin{array}{c}-1.11 * * \\
(0.34)\end{array}$ \\
\hline & NDVI & 0.65 & $\begin{array}{c}4.84^{* *} \\
(0.70) \\
\end{array}$ & $\begin{array}{c}-1.11 * * \\
(0.32)\end{array}$ \\
\hline & RVI & 0.69 & $\begin{array}{c}0.66 * * \\
(0.09)\end{array}$ & $\begin{array}{c}-0.75 * * \\
(0.25)\end{array}$ \\
\hline
\end{tabular}

$310 *$ significant at 5\% level, ** significant at $1 \%$ level.

311 4.3. Estimating and validating the reference LAI maps based on GR models

312 Figure 4 presents the reference LAI maps estimated by the GR models based on

313 Table 3. The validation results are shown in Figure 5 and Table 4. Most of the $\mathrm{R}^{2}$ values

314 in Table 4 are nearly equal to the $\mathrm{R}^{2}$ values in Table 3, which indicates that the GR

315 models are robust. However, some GR models may not be robust (e.g., GR model with

316 DVI for corn at the AGRO site). We discuss the problem in detail at the end of this 
317 section. As mentioned in section 4.2, the low $\mathrm{R}^{2}$ values for GR models at the AGRO,

318 Plan-de-dieu, and Hulun Buir sites may be due to the poor relationships of DVI, NDVI,

319 and RVI with in situ LAI observations. For example, there is one very low in situ LAI

320 observation at the AGRO (corn) and Plan-die-dieu sites, and one very high in situ LAI

321 observation at the Hulun Buir site. These abnormal in situ LAI observations may be

322 owing to measurement errors. Regardless, the $\mathrm{R}^{2}$ values show the same pattern as that in

323 section 4.2. That is, in terms of $\mathrm{R}^{2}$ values, the GR models with DVI have the best

324 performance over the two cropland sites, while the GR models with DVI at the two

325 grassland sites perform more poorly. The values of root mean square errors (RMSE)

326 indicate that all the sites have the same trend within same vegetation types, excepting for

327 the Plan-de-dieu site. The RMSE values are lowest for DVI at the AGRO site (0.88 for

328 corn and 0.59 for soybean). This implies that the standard deviation of the differences

329 between the estimated LAI based on DVI and the field LAI is lowest. However, at the

330 Hunlun Buir and Zhangbei sites, the RMSE values are highest for DVI (0.40 and 0.46,

331 respectively). In terms of bias, there are no clear common characteristics. For example,

332 the value of absolute bias for the AGRO (corn) site is lowest based on DVI, while for the

333 AGRO (soybean) site, the value of absolute bias is lowest based on RVI. In summary, the

334 GR models based on DVI have the best estimations for the two cropland sites, while for

335 the two grassland sites, the GR models based on DVI perform poorly.

336 Table 4. Statistics of estimated LAI of the GR and RMA models compared to the in situ 337 LAI.

\begin{tabular}{cccccccc}
\hline \multirow{2}{*}{ Site } & \multirow{2}{*}{ VIs } & \multicolumn{2}{c}{$\mathbf{R}^{2}$} & \multicolumn{2}{c}{ RMSE } & \multicolumn{2}{c}{ bias } \\
\cline { 3 - 8 } & & GR & RMA & GR & RMA & GR & RMA \\
\hline \multirow{3}{*}{ AGRO } & DVI & 0.23 & 0.23 & 0.88 & 0.89 & 0.05 & 0.10 \\
\cline { 2 - 8 } & NDVI & 0.18 & 0.18 & 0.94 & 1.10 & -0.17 & 0.01 \\
\hline
\end{tabular}




\begin{tabular}{cccccccc}
\hline (Corn) & RVI & 0.17 & 0.17 & 0.94 & 1.10 & -0.16 & 0.01 \\
\hline \multirow{3}{*}{$\begin{array}{c}\text { AGRO } \\
\text { (Soybean) }\end{array}$} & DVI & 0.43 & 0.43 & 0.59 & 0.68 & -0.15 & -0.22 \\
\cline { 2 - 7 } & NDVI & 0.29 & 0.29 & 0.73 & 0.99 & -0.22 & -0.33 \\
\cline { 2 - 7 } & RVI & 0.38 & 0.38 & 0.60 & 0.68 & -0.12 & -0.16 \\
\hline \multirow{3}{*}{ Plan-de-dieu } & DVI & 0.52 & 0.52 & 0.16 & 0.17 & 0.10 & -0.12 \\
\cline { 2 - 8 } & NDVI & 0.43 & 0.43 & 0.16 & 0.17 & 0.08 & -0.10 \\
\cline { 2 - 8 } & RVI & 0.45 & 0.45 & 0.16 & 0.17 & 0.08 & -0.10 \\
\hline \multirow{3}{*}{ HulunBuir } & DVI & 0.45 & 0.45 & 0.40 & 0.43 & -0.11 & -0.12 \\
\cline { 2 - 8 } & NDVI & 0.55 & 0.55 & 0.39 & 0.48 & -0.14 & -0.15 \\
\cline { 2 - 8 } & RVI & 0.56 & 0.56 & 0.38 & 0.43 & -0.15 & -0.16 \\
\hline \multirow{2}{*}{ Zhangbei } & DVI & 0.53 & 0.53 & 0.46 & 0.52 & -0.02 & 0.02 \\
\cline { 2 - 8 } & NDVI & 0.67 & 0.67 & 0.38 & 0.42 & -0.01 & 0.02 \\
\cline { 2 - 7 } & RVI & 0.63 & 0.63 & 0.43 & 0.50 & 0.05 & 0.10 \\
\hline
\end{tabular}

338

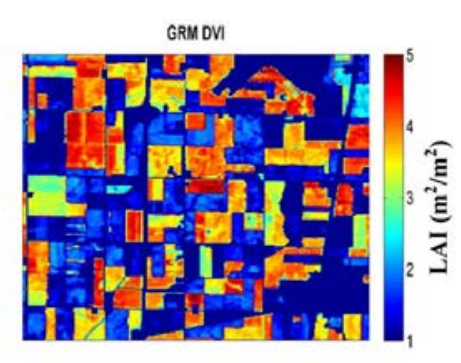

(1)

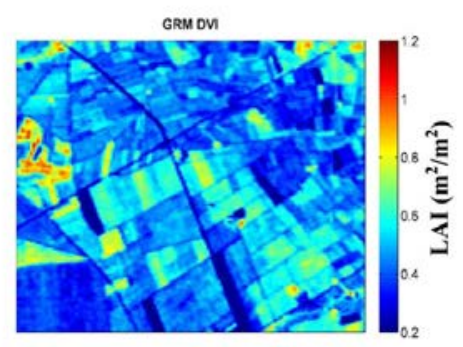

(4)

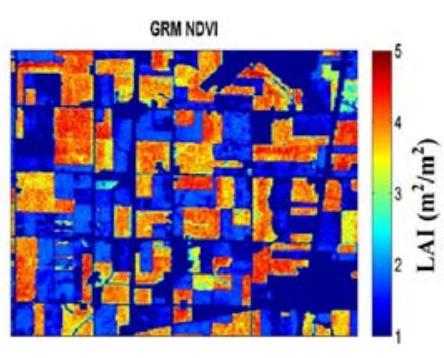

(2)

AGRO

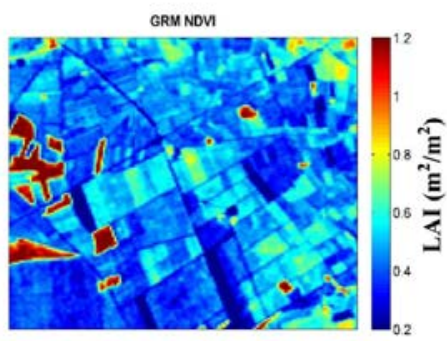

(5)

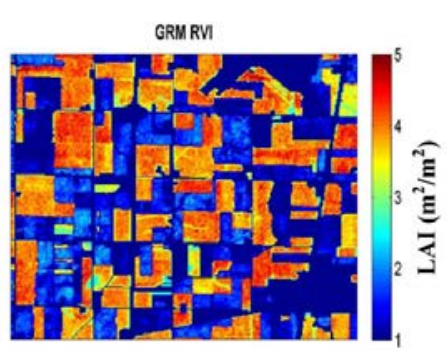

(3)

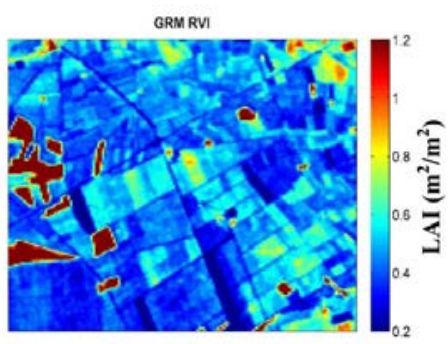

(6)

Plan-de-dieu 


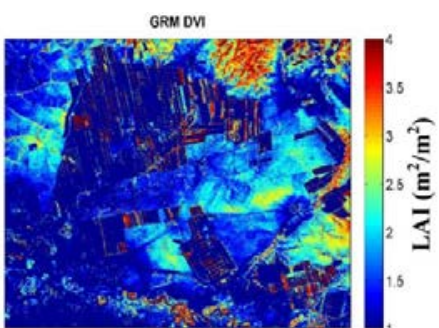

(7)

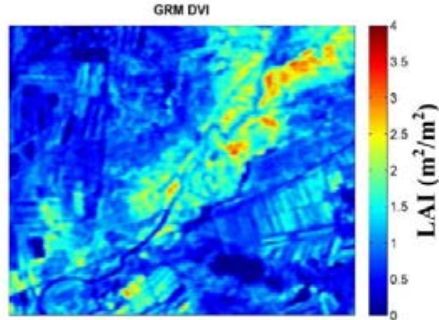

(10)

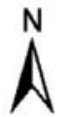

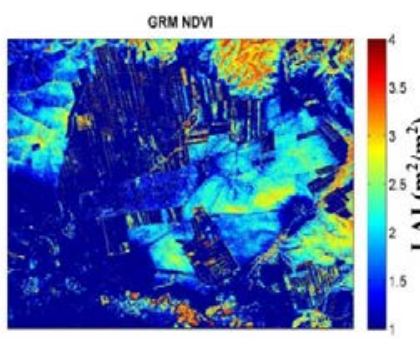

(8)

Hulun Buir

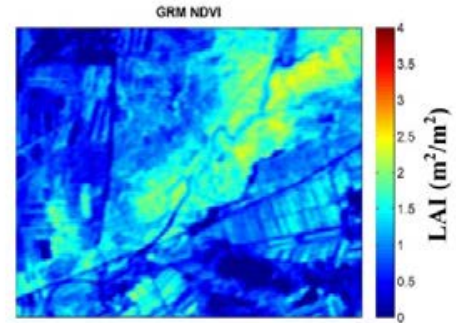

(11)

Zhangbei

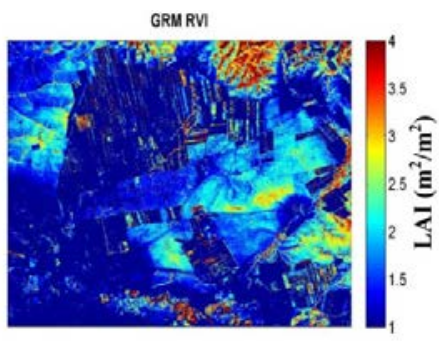

(9)

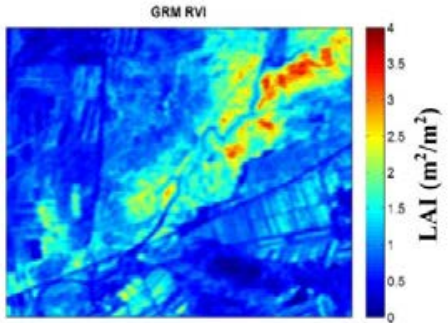

(12)

Figure 4. Reference LAI maps estimated by the GR models at the AGRO, Plan-de-dieu, $\begin{array}{ll}341 & \text { Figure 4. Reference LAI maps } \\ 342 & \text { Hulun Buir, and Zhangbei sites. }\end{array}$

343

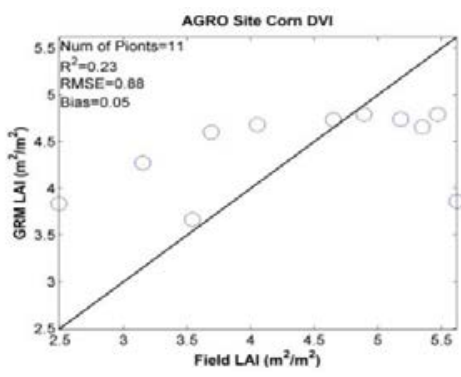

(1)

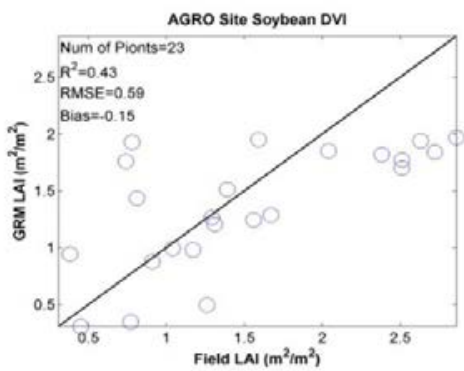

(4)

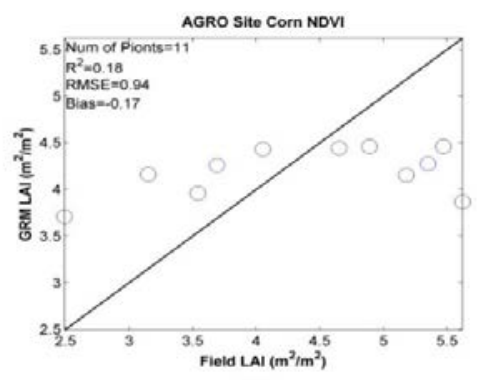

(2)

AGRO (Corn)

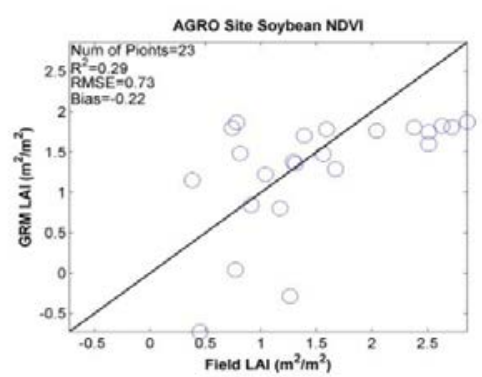

(5)

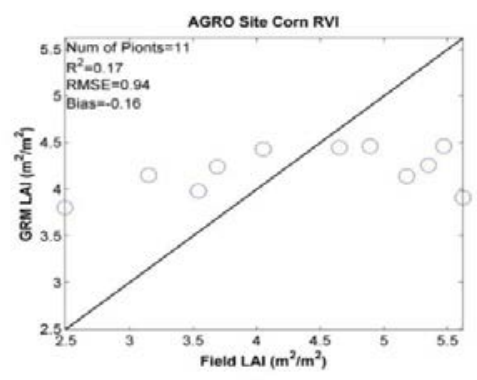

(3)

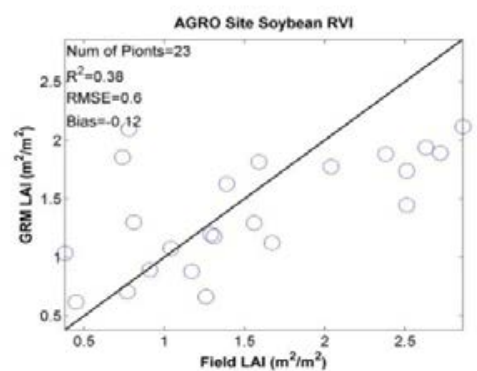

(6)

AGRO (Soybean) 


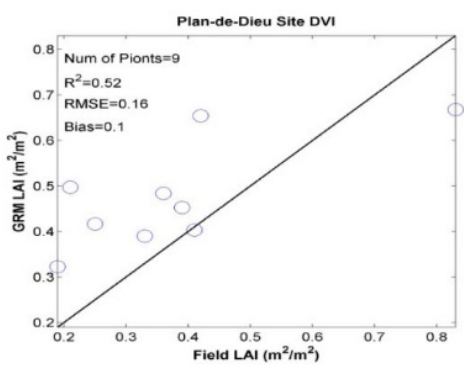

(7)

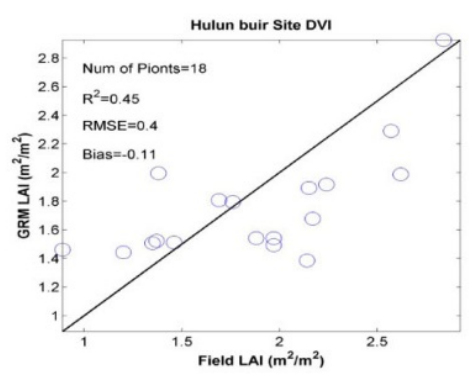

(10)

345

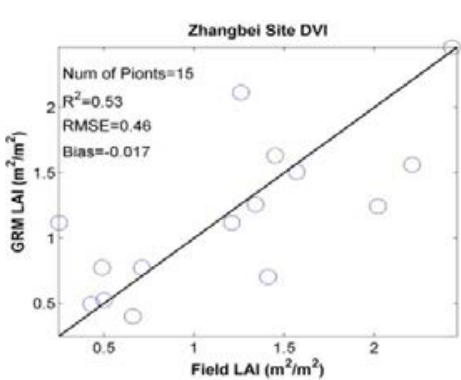

(13)

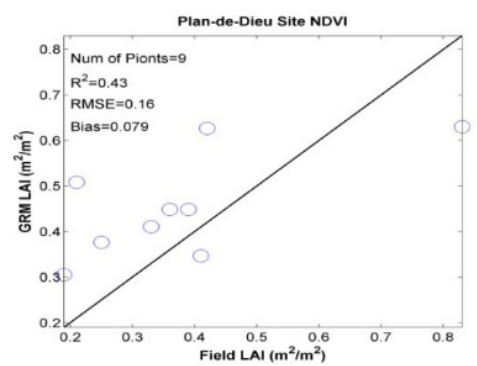

(8)

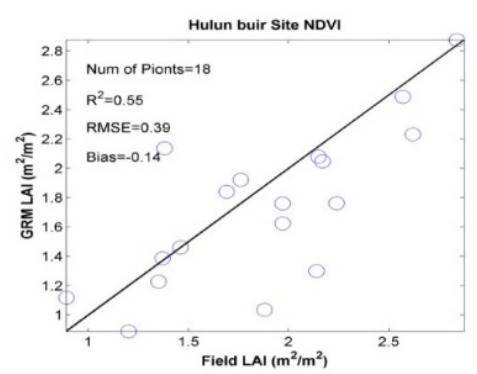

(11)

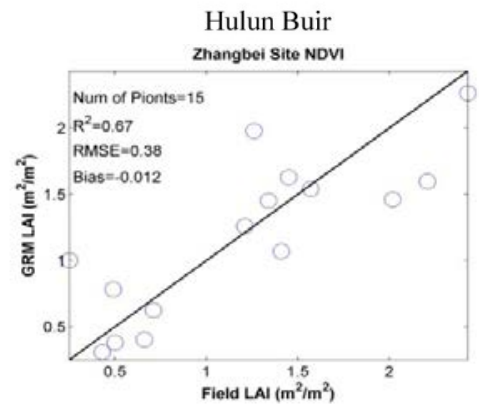

(14)

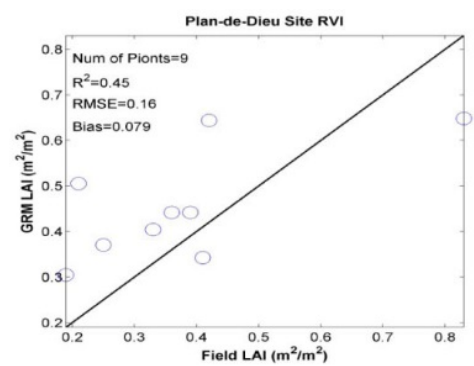

(9)

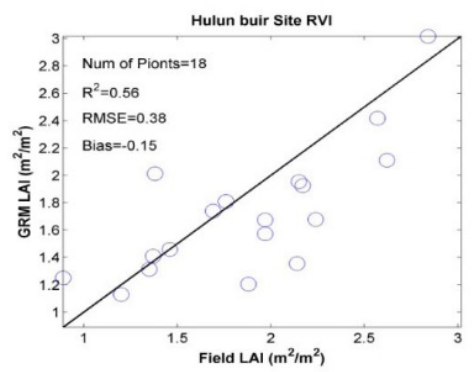

(12)

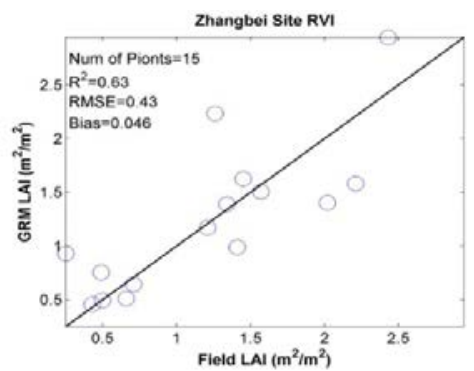

(15)
346

347

348

349

350

351

352

353 five times by randomly selecting 65\% of the LAI points for establishing the GR models,

354 with the remainder of the LAI points used for model validation. The mean RMSE values

355 ( $\left.\mu_{\mathrm{RMSE}}\right)$ of the five repetitions were calculated following previous studies Lee et al.

356 (2008a, b). Figure 6 shows the results of cross validation. The blue bar is the $\mu_{\mathrm{RMSE}}$ of the 
357 five repetitions for each GR model, the black error bar is $\mu_{\text {RMSE }} \pm \sigma_{\text {RMSE }}$ ( $\sigma_{\text {RMSE }}$ is the

358 standard deviation) of the five repetitions for each GR model, and the brown square is the

359 RMSE value from Table 4. In comparison to the $\mu_{\mathrm{RMSE}}$ in Figure 6, most of the RMSE

360 values in Table 4 are nearly within $\left[\mu_{\mathrm{RMSE}}-\sigma_{\mathrm{RMSE}}, \mu_{\mathrm{RMSE}}+\sigma_{\mathrm{RMSE}}\right]$, which indicates that

361 the GR models are robust. The RMSE value of the GR model for DVI at the AGRO

362 (corn) site slightly exceeds the upper limits of the error bar ( $\left.\mu_{\mathrm{RMSE}}+\sigma_{\mathrm{RMSE}}\right)$, which

363 confirms that the GR model with DVI for corn at the AGRO site is not robust. This is

364 presumably due to the poor association of DVI and the in situ LAI values (Figure 2). The

365 RMSE values of the GR model for DVI and RVI at the Zhangbei site also exceed upper

366 limits of the error bar, which may be due to the limited repetitions. More repetitions are

367 needed for robust validation.
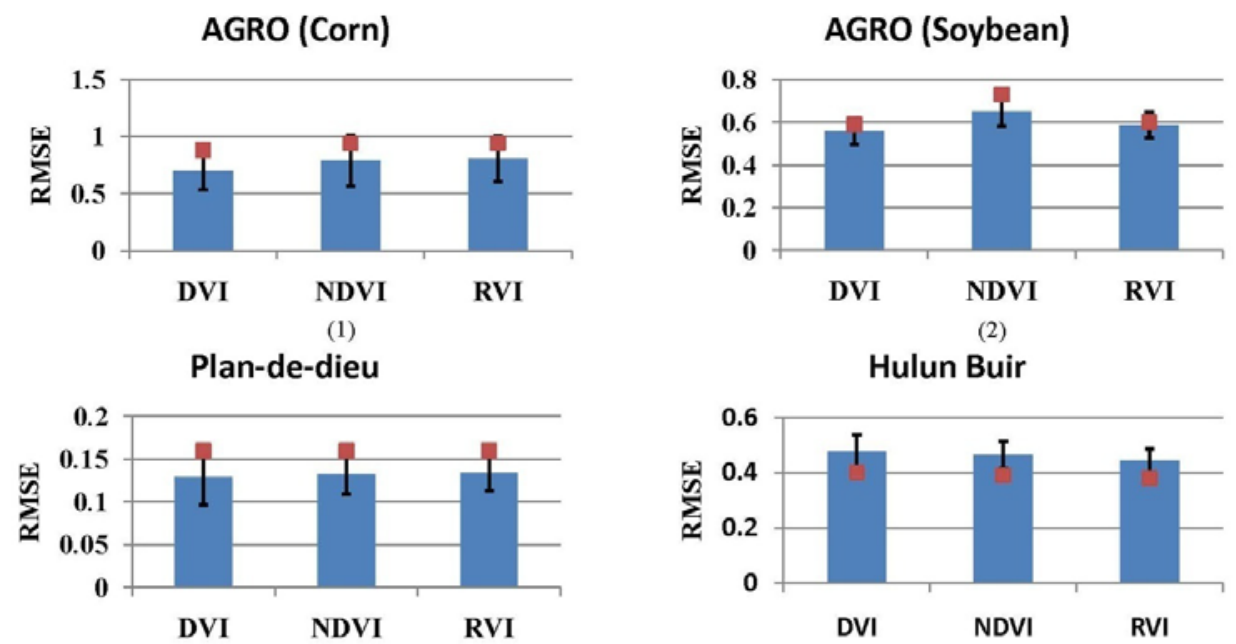

Zhangbei

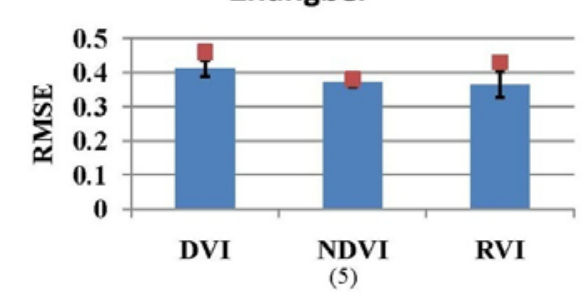

Cross validated mean

RMSE

- GRM RMSE

368

369 Figure 6. Cross validation for the GR models 
371 For robust assessment of the performance of the GR models, the results from the

372 GR and RMA models were compared. Based on equation (5), the high resolution

373 reference LAI maps estimated by the RMA model are depicted in Figure 7. The

374 validation results are displayed in Figure 8 and Table 4. In terms of $\mathrm{R}^{2}$, the GR models

375 have identical values with the RMA models at the four study sites. The RMSE values for

376 the GR models are lower than the RMA models for all of the sites, which may due to the

377 consideration of spatial correlations of regression residuals. The GR models have lower

378 biases than the RMA models, excluding the GR models with NDVI and RVI at the

379 AGRO (corn) site. In summation, the GR models improve the accuracy of reference LAI

380 maps compared to the RMA models.

381 In addition, the GR and RMA models had consistent performance at cropland and

382 grassland sites. Both GR and RMA models have the best estimating ability based on DVI

383 at the cropland sites (AGRO and Plan-de-dieu sites), while the GR and RMA models

384 perform poorly based on DVI at the grassland sites (Hulun Buir and Zhangbei sites). 


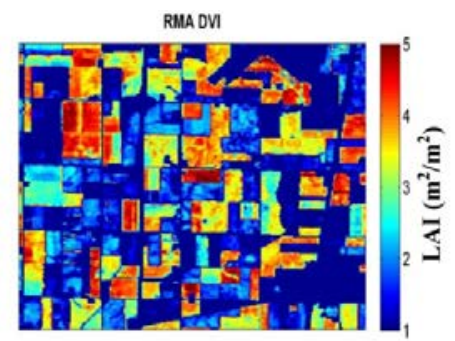

(1)

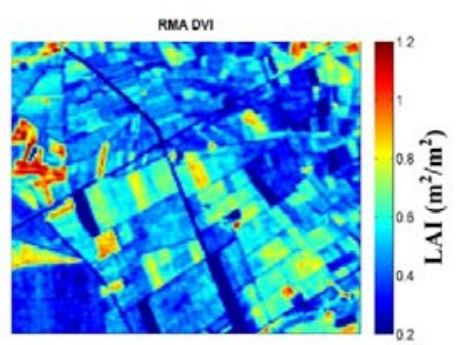

(4)

386

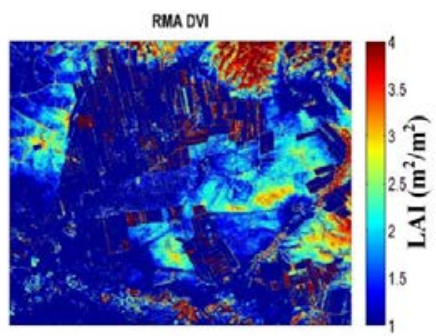

(7)

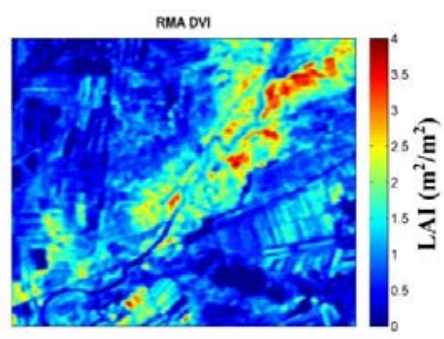

(10)

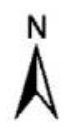

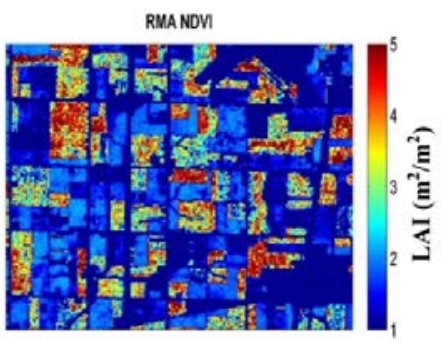

(2)

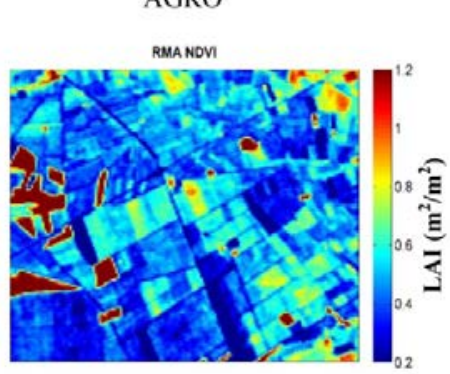

(5)

Plan-de-dieu

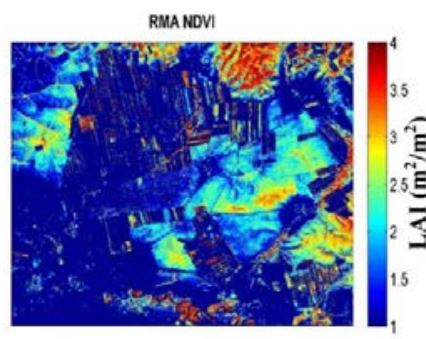

(8)

Hulun Buir

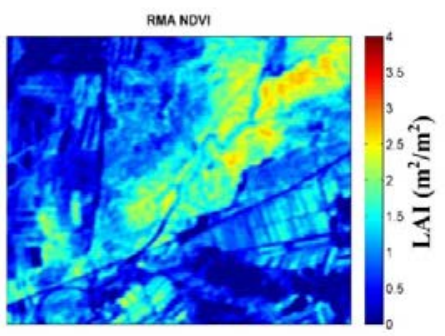

(11)

Zhangbei

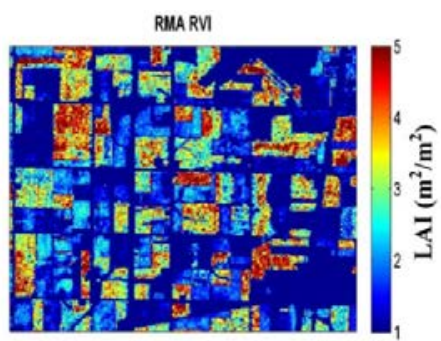

(3)

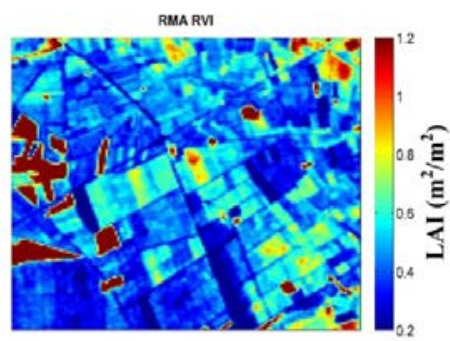

(6)

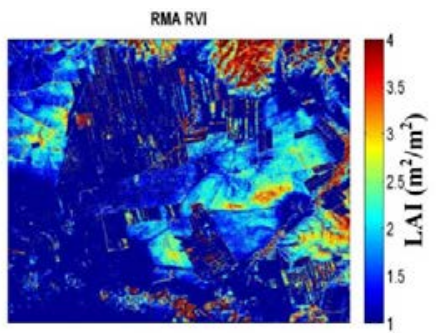

(9)

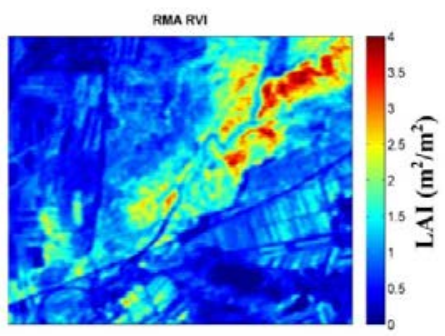

(12)

388 Figure 7. Reference LAI maps estimated by the RMA models at the AGRO, Plan-de389 dieu, Hulun Buir, and Zhangbei sites.

390

391 


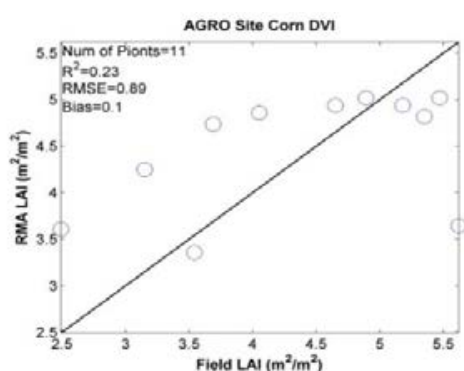

(1)

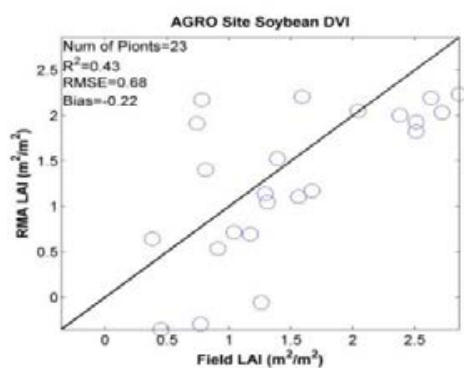

(4)

392

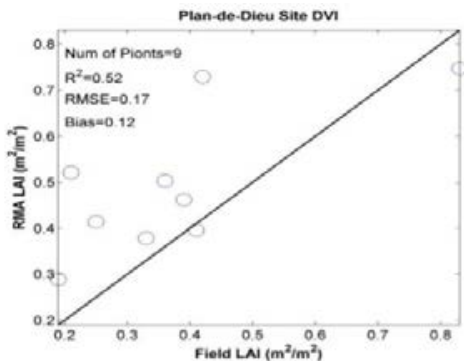

(7)

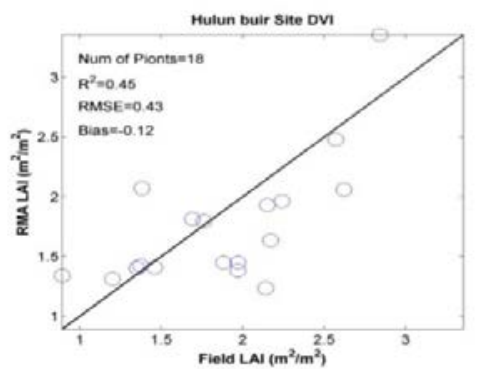

(10)

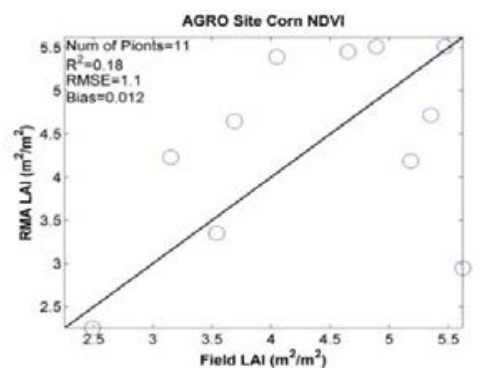

(2)

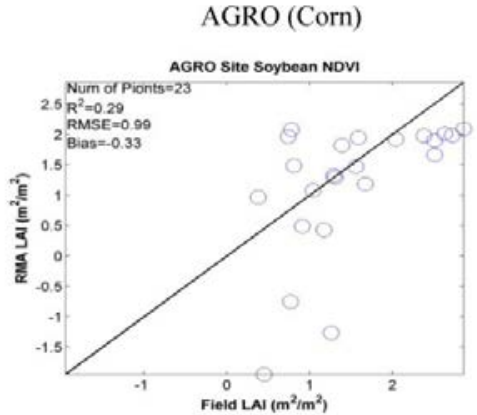

(5)

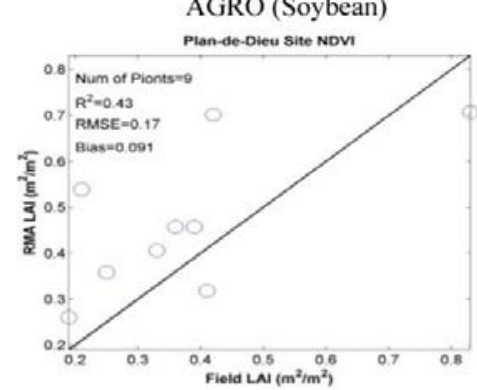

(8)

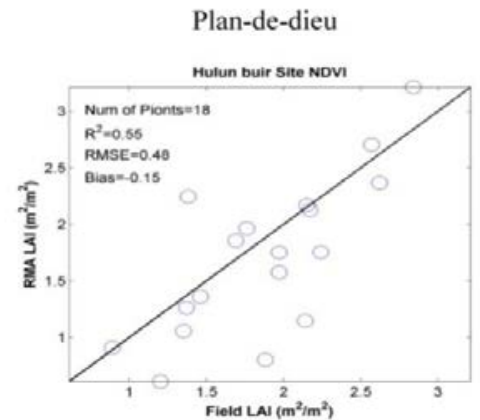

(11)

Hulun Buir

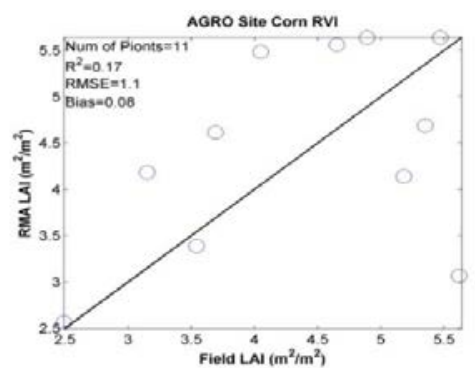

(3)

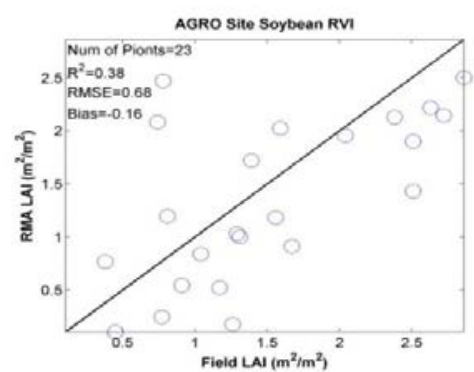

(6)

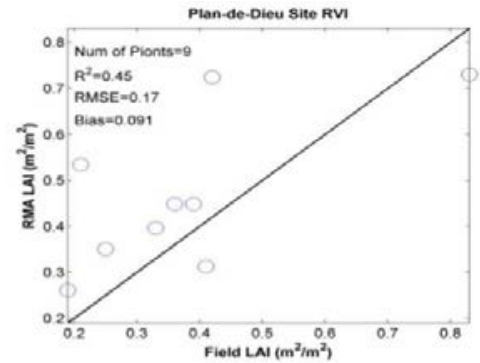

(9)

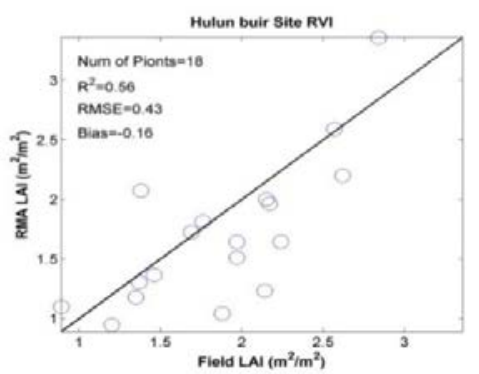

(12) 


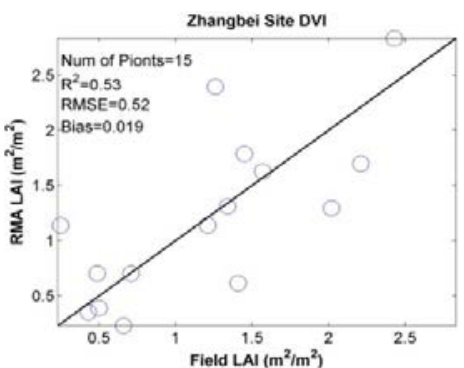

(13)

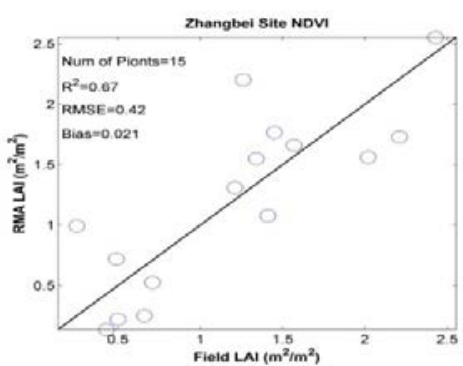

(14)

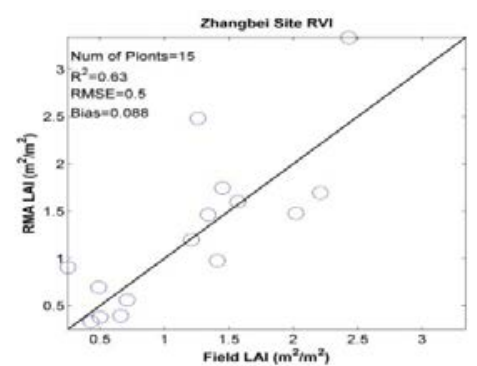

(15)
394

395

396

397

398

399

400

401

402

403

404 resolution remote sensing products is using fine reference maps derived from up-scaling

405 in situ measurements. This study up-scaled the field LAI measurements to high resolution

406 LAI reference map through linking the in situ LAI measurements and Landsat TM/ETM+

407 and SPOT-HRV data using the geostatistical regression method. To analyze the

408 discrepancy of employing different vegetation indices on estimating LAI reference maps,

409 this study established the GR models for DVI, NDVI and RVI. To further assess the

410 performance of the GR model, this study compared the results from GR and RMA

411 models. The results show that the performances of GR models over the cropland and

412 grassland sites are different. The GR models based on DVI provide the best estimation at

413 the cropland sites (AGRO and Plan-de-dieu sites), while the GR models perform poorly

414 based on DVI at the grassland sites (Hulun Buir and Zhangbei sites). By considering the 
415 spatial/temporal correlations of in situ LAI observations and high resolution DVI, NDVI,

416 and RVI data, this study reveals that the performance of the GR models is better than the

417 RMA models in terms of RMSE and bias.

418 In summary, the GR method inherits the merits from both traditional geostatistical

419 methods and regression methods. Compared to regression methods (e.g., RMA), the GR

420 method is improved in accounting for the spatial/temporal correlation of residuals from

421 the regressions of LAI observations and high resolution remote sensing data (e.g., DVI,

422 NDVI and RVI data in this study). In contrast to traditional geostatistcal methods (e.g.,

423 Kriging), the GR method attempts to provide better estimating of unknown points by

424 exploring the association between high resolution remote sensing data and field

425 observations. Our study confirmed the performance of the GR models is better than the

426 RMA models in terms of RMSE and bias, which indicates the potential of GR method to

427 up-scale other in situ biophysical and geophysical measurements (e.g., fAPAR and soil

428 moisture) to high resolution reference data to validate other coarse resolution products.

430 Acknowledgments

431 This work was jointly supported by the National Key Basic Research Program of 432 China (973 Program) Project (Grant No. 2013CB733403), the National Natural Science 433 Foundation of China (Grant No. 41271347 and 91125004), and the High-Tech Research

434 and Development Program of China (863 Program) Project (Grant No. 2012AA12A305).

435 We thank Dr. Gaolong Zhu from the Department of Geography at Minjiang University, 436 BigFoot project, VALERI project, and USGS for providing in situ LAI measurements, 437 SPOT-HRV data, and Landsat TM/ETM+ data. We are grateful to Dr. Anna Michalak’s 
438 team in the Department of Global Ecology, the Carnegie Institution for Science for

439 providing original GR Matlab code. We appreciate Matthew Purtill and Jothiganesh

440 Shanmugasundaram in the Department of Geology and Geography, West Virginia

441 University for their helpful comments in improving the English language. We also

442 appreciate two anonymous referees for their valuable suggestions to make the manuscript

443 better. 


\section{References}

445 Abuelgasim, A.A., Fernandes, R.A., Leblanc, S.G., 2006. Evaluation of national and

446

447

448

449

450

451

452

453

454

455

456

457

458

459

460

461

462

463

464

465

466

467

468

469

470

471

472

473

474

475

476

477

478

479

480

481

482

483

484

485

486

487

488

global LAI products derived from optical remote sensing instruments over

Canada. IEEE Transactions on Geoscience and Remote Sensing 44, 1872-1884.

Aitken, A.C., 1935. On least squares and linear combinations of observations.

Proceedings of the Royal Society of Edinburgh 55, 42-48.

Baret, F., Weiss, M., Allard, D., Garrigues, S., Leroy, M., Jeanjean, H., Fernandes, R., Myneni, R., Privette, J., Morisette, J., 2005. VALERI: a network of sites and a methodology for the validation of medium spatial resolution land satellite products. Remote Sensing of Environment, in press.

Berterretche, M., Hudak, A.T., Cohen, W.B., Maiersperger, T.K., Gower, S.T., Dungan, J., 2005. Comparison of regression and geostatistical methods for mapping Leaf Area Index (LAI) with Landsat ETM+ data over a boreal forest. Remote Sensing of Environment 96, 49-61.

BigFoot, 1999. Linking In Situ Measurements, Remote Sensing, and Models to Validate MODIS Products Related to the Terrestrial Carbon Cycle. http://www.fsl.orst.edu/larse/bigfoot/ovr_dsgn.html (accessed 01.02.2016).

Chatfield, C., 2003. The analysis of time series: an introduction. CRC press, Boca Raton.

Chen, J.M., Black, T., 1992. Defining leaf area index for non- flat leaves. Plant, Cell \& Environment 15, 421-429.

Chen, J.M., Pavlic, G., Brown, L., Cihlar, J., Leblanc, S., White, H., Hall, R., Peddle, D., King, D., Trofymow, J., 2002. Derivation and validation of Canada-wide coarseresolution leaf area index maps using high-resolution satellite imagery and ground measurements. Remote Sensing of environment 80, 165-184.

Cohen, W.B., Justice, C.O., 1999. Validating MODIS terrestrial ecology products: linking in situ and satellite measurements. Remote Sensing of Environment 70, 13.

Cohen, W.B., Maiersperger, T.K., Gower, S.T., Turner, D.P., 2003. An improved strategy for regression of biophysical variables and Landsat ETM+ data. Remote Sensing of Environment 84, 561-571.

Colombo, R., Bellingeri, D., Fasolini, D., Marino, C.M., 2003. Retrieval of leaf area index in different vegetation types using high resolution satellite data. Remote Sensing of environment 86, 120-131.

Erickson, T.A., Williams, M.W., Winstral, A., 2005. Persistence of topographic controls on the spatial distribution of snow in rugged mountain terrain, Colorado, United States. Water Resources Research 41, W04014.

Fernandes, R., Plummer, S., Nightingale, J., Baret, F., Camacho, F., Fang, H., Garrigues, S., Gobron, N., Lang, M., Lacaze, R., LeBlanc, S., Meroni, M., Martinez, B., Nilson, T., Pinty, B., Pisek, J., Sonnentag, O., Verger, A., Welles, J., Weiss, M., Widlowski, J.L., 2014. Global Leaf Area Index Product Validation Good Practices, in: Schaepman-Strub, G., Román, M., Nickeson, J. (Eds.), Best Practice for Satellite-Derived Land Product Validation. Land Product Validation Subgroup (WGCV/CEOS).

Garrigues, S., Lacaze, R., Baret, F., Morisette, J., Weiss, M., Nickeson, J., Fernandes, R., Plummer, S., Shabanov, N., Myneni, R., 2008. Validation and intercomparison of 
global Leaf Area Index products derived from remote sensing data. Journal of Geophysical Research 113, G02028.

Gong, P., Wang, J., Yu, L., Zhao, Y., Zhao, Y., Liang, L., Niu, Z., Huang, X., Fu, H., Liu, S., 2013. Finer resolution observation and monitoring of global land cover: first mapping results with Landsat TM and ETM+ data. International Journal of Remote Sensing 34, 2607-2654.

Huang, D., Yang, W., Tan, B., Rautiainen, M., Zhang, P., Hu, J., Shabanov, N.V., Linder, S., Knyazikhin, Y., Myneni, R.B., 2006. The importance of measurement errors for deriving accurate reference leaf area index maps for validation of moderateresolution satellite LAI products. IEEE Transactions on Geoscience and Remote Sensing 44, 1866-1871.

Huete, A., Didan, K., Miura, T., Rodriguez, E.P., Gao, X., Ferreira, L.G., 2002. Overview of the radiometric and biophysical performance of the MODIS vegetation indices. Remote sensing of environment 83, 195-213.

Iiames, J.S., Congalton, R.G., Lewis, T.E., Pilant, A.N., 2015. Uncertainty Analysis in the Creation of a Fine-Resolution Leaf Area Index (LAI) Reference Map for Validation of Moderate Resolution LAI Products. Remote Sensing 7, 1397-1421.

Kang, J., Jin, R., Li, X., 2015. Regression Kriging-Based Upscaling of Soil Moisture Measurements From a Wireless Sensor Network and Multiresource Remote Sensing Information Over Heterogeneous Cropland. IEEE Geoscience and Remote Sensing Letters 12, 92-96.

Kitanidis, P.K., Shen, K.-F., 1996. Geostatistical interpolation of chemical concentration. Advances in Water Resources 19, 369-378.

Knyazikhin, Y., Martonchik, J., Myneni, R., Diner, D., Running, S., 1998. Synergistic algorithm for estimating vegetation canopy leaf area index and fraction of absorbed photosynthetically active radiation from MODIS and MISR data. Journal of Geophysical Research 103, 32257-32276.

Lee, E., Chase, T.N., Rajagopalan, B., 2008a. Highly improved predictive skill in the forecasting of the East Asian summer monsoon. Water resources research 44.

Lee, E., Chase, T.N., Rajagopalan, B., 2008b. Seasonal forecasting of East Asian summer monsoon based on oceanic heat sources. International Journal of Climatology 28, 667-678.

Leung, S., Cooley, D., 2014. A comparison of a traditional geostatistical regression approach and a general Gaussian process approach for spatial prediction. Stat 3, 228-239.

Li, A., Bo, Y., Chen, L., 2013a. Bayesian maximum entropy data fusion of field-observed leaf area index (LAI) and Landsat Enhanced Thematic Mapper Plus-derived LAI. International Journal of Remote Sensing 34, 227-246.

Li, A., Bo, Y., Zhu, Y., Guo, P., Bi, J., He, Y., 2013b. Blending multi-resolution satellite sea surface temperature (SST) products using Bayesian maximum entropy method. Remote Sensing of Environment 135, 52-63.

Liang, S., Fang, H., Chen, M., 2001. Atmospheric correction of Landsat ETM+ land surface imagery. I. Methods. IEEE Transactions on Geoscience and Remote Sensing 39, 2490-2498.

Liang, S., Zhang, X., Xiao, Z., Cheng, J., Liu, Q., Zhao, X., 2014. Challenges and Prospects, Global LAnd Surface Satellite (GLASS) Products. Springer, Berlin. 
535

536

537

538

539

540

541

542

543

544

545

546

547

548

549

550

551

552

553

554

555

556

557

558

559

560

561

562

563

564

565

566

567

568

569

570

571

572

573

574

575

576

577

578

579

Martinez, B., Cassiraga, E., Camacho, F., Garcia-Haro, J., 2010. Geostatistics for mapping leaf area index over a cropland landscape: Efficiency sampling assessment. Remote Sensing 2, 2584-2606.

Martinez, B., García-Haro, F., Camacho-de Coca, F., 2009. Derivation of high-resolution leaf area index maps in support of validation activities: Application to the cropland Barrax site. Agricultural and Forest Meteorology 149, 130-145.

Masek, J.G., Vermote, E.F., Saleous, N.E., Wolfe, R., Hall, F.G., Huemmrich, K.F., Gao, F., Kutler, J., Lim, T.-K., 2006. A Landsat surface reflectance dataset for North America, 1990-2000. IEEE Geoscience and Remote Sensing Letters 3, 68-72.

Morisette, J.T., Baret, F., Privette, J.L., Myneni, R.B., Nickeson, J.E., Garrigues, S., Shabanov, N.V., Weiss, M., Fernandes, R.A., Leblanc, S.G., 2006. Validation of global moderate-resolution LAI products: A framework proposed within the CEOS land product validation subgroup. IEEE Transactions on Geoscience and Remote Sensing 44, 1804-1817.

Mueller, K.L., Yadav, V., Curtis, P.S., Vogel, C., Michalak, A.M., 2010. Attributing the variability of eddy- covariance $\mathrm{CO} 2$ flux measurements across temporal scales using geostatistical regression for a mixed northern hardwood forest. Global Biogeochemical Cycles 24.

Myneni, R.B., Ramakrishna, R., Nemani, R., Running, S., 1997. Estimation of global leaf area index and absorbed PAR using radiative transfer models. IEEE Transactions on Geoscience and Remote Sensing 35, 1380-1393.

Pisek, J., Chen, J.M., 2007. Comparison and validation of MODIS and VEGETATION global LAI products over four BigFoot sites in North America. Remote Sensing of Environment 109, 81-94.

Rossello, P., 2007. Ground data processing \& production of the level 1 high resolution maps VALERI 2004 plan-de-dieu

site http://w3.avignon.inra.fr/valeri/Europe/France/PACA/Plan-dedieu/2004/biomap/PlandeDieu2004FTReport.pdf (accessed 17.07.2015).

Rossello, P., 2008. Ground data processing \& production of the level 1 high resolution maps VALERI 2002 zhangbei site http://w3.avignon.inra.fr/valeri/asie/chine/zhangbei/2002/biomap/ZhangBei20 02FTReport.pdf (accessed 17.07.2015).

Schabenberger, O., Pierce, F.J., 2001. Statistical models for spatial data, in: Schabenberger, O., Pierce, F.J. (Eds), Contemporary statistical models for the plant and soil sciences. CRC press, Boca Raton, pp. 561-697.

Smith, R.J., 2009. Use and misuse of the reduced major axis for line- fitting. American Journal of Physical Anthropology 140, 476-486.

Tian, Y., Zhang, Y., Knyazikhin, Y., Myneni, R.B., Glassy, J.M., Dedieu, G., Running, S.W., 2000. Prototyping of MODIS LAI and FPAR algorithm with LASUR and LANDSAT data. IEEE Transactions on Geoscience and Remote Sensing 38, 2387-2401.

Van der Meer, F., 2012. Remote-sensing image analysis and geostatistics. International Journal of Remote Sensing 33, 5644-5676.

Van der Meer, F., Bakker, W., Scholte, K., Skidmore, A., De Jong, S., Clevers, J., Addink, E., Epema, G., 2001. Spatial scale variations in vegetation indices and 
above-ground biomass estimates: implications for MERIS. International Journal of Remote Sensing 22, 3381-3396.

Wang, J., Ge, Y., Song, Y., Li, X., 2014. A Geostatistical Approach to Upscale Soil Moisture With Unequal Precision Observations. IEEE Geoscience and Remote Sensing Letters 11, 2125-2129.

Weiss, M., Baret, F., Garrigues, S., Lacaze, R., 2007. LAI and fAPAR CYCLOPES global products derived from VEGETATION. Part 2: validation and comparison with MODIS collection 4 products. Remote sensing of Environment 110, 317331.

Xiao, Z., Liang, S., Wang, J., Chen, P., Yin, X., Zhang, L., Song, J., 2014. Use of general regression neural networks for generating the GLASS leaf area index product from time-series MODIS surface reflectance. IEEE Transactions on Geoscience and Remote Sensing 52, 209-223.

Yadav, V., Mueller, K., Dragoni, D., Michalak, A., 2010. A geostatistical synthesis study of factors affecting gross primary productivity in various ecosystems of North America. Biogeosciences 7, 2655-2671.

Yang, W., Tan, B., Huang, D., Rautiainen, M., Shabanov, N.V., Wang, Y., Privette, J.L., Huemmrich, K.F., Fensholt, R., Sandholt, I., 2006. MODIS leaf area index products: From validation to algorithm improvement. IEEE Transactions on Geoscience and Remote Sensing 44, 1885-1898.

Yu, L., Wang, J., Clinton, N., Xin, Q., Zhong, L., Chen, Y., Gong, P., 2013. FROM-GC: $30 \mathrm{~m}$ global cropland extent derived through multisource data integration. International Journal of Digital Earth 6, 521-533. 